\title{
The Limits of Child Agency?
}

\section{Dissonances and Contradictions in Conceptualisations of Agency within Child-Led Marriages in Somalia and Cameroon}

\author{
Michelle Lokot \\ London School of Hygiene \& Tropical Medicine, London, UK \\ Corresponding author \\ michelle.lokot@lshtm.ac.uk \\ Holly Baker Shakya \\ Center on Gender Equity and Health, School of Medicine, \\ University California San Diego, CA, USA \\ hshakya@health.ucsd.edu \\ Beniamino Cislaghi \\ London School of Hygiene \& Tropical Medicine, London, UK \\ ben.cislaghi@lshtm.ac.uk
}

\begin{abstract}
This article explores how communities and development practitioners conceptualise children's agency. It highlights contradictions within non-government organisations (NGO) and United Nations (UN) narratives on child marriage: children are said to exercise agency when they defy forced marriage, yet they lack knowledge and choice if they themselves decide to marry. This article is based on interviews and focus group discussions with communities in Somalia and Cameroon, and interviews with development practitioners in both countries. The findings highlight four themes: child-led marriages are a newer practice; child-led marriages are often temporary; practitioners believe children are too young to exercise agency; and practitioners question whether children can make decisions. These findings have implications for child marriage interventions, highlighting the need for "agency" to be conceptualised less narrowly. For NGO s, UN agencies and policy-makers, requires reflecting on what it means to accept community choices, irrespective of whether the outcome is positive or negative.
\end{abstract}




\section{Keywords}

agency - child marriage - gender - child rights - child protection

\section{Introduction}

Child marriage - formal or informal unions where one or both spouses are under the age of 18 (UNICEF, 2018) - affects millions of girls and boys worldwide. Despite child marriage involving both girls and boys, most attention has focused on its causes and consequences for girls, which may be a reflection of the more serious negative consequences for girls (UNICEF, 2018). These consequences include: poor maternal health (Gage, 2013; de Groot $e t$ al., 2018), reduced access to health services (Nasrullah et al., 2013; Sekine and Carter, 2019), school drop-out (Bajracharya et al., 2019), gender-based violence (Erulkar, 2013; Kidman, 2017), and negative health outcomes for girls' children (de Groot et al., 2018; Raj et al., 2010). For boys, while existing studies are limited, a recent systematic review suggests the consequences include pressures to take on adult responsibilities and early fatherhood which might limit their educational and employment opportunities (Gastón et al., 2019).

Among the many factors contributing to child marriage, the literature often mentions economic deprivation (Paul, 2019), forced displacement (Mourtada et al., 2017) and social norms (Dean et al., 2019; McDougal et al., 2018). Aiming to address its harmful consequences, global health actors, non-government organisations (NGO s) and United Nations (UN) agencies have sought to end child marriage through a variety of strategies (Kalamar et al., 2016; Malhotra et al., 2011). Most common interventions include sharing information on the negative consequences of child marriage with girls and their families (Warner et al., 2016), legal reform (Arthur et al., 2018), economic incentives for delaying girls' marriage (Shahnaz and Karim, 2008; Sinha and Yoong, 2009), promoting girls' access to formal education (Erulkar and Muthengi, 20o9; Mehra et al., 2018) and changing social norms underpinning the practice (Cislaghi and Bhattacharjee, 2017; Watson, 2014).

Much scholarly and NGO attention has focused on how to reduce instances of child marriage where girls are forced or induced to marry. Forced marriage is different than arranged marriage, where families plan a union and couples consent to marry. Less effort has been dedicated to studying marriages initiated by children or adolescents themselves (Bantebya et al., 2014; Horii, 2020a; Kenny et al., 2019; Taylor et al., 2019). Adolescent- and child-led marriages (from now on, just "child-led marriages") offer opportunities to investigate a critically 
important tension in the gender equality and child protection industries. The tension we refer to is between protecting and promoting children's (especially girls') health and wellbeing on the one hand, and respecting and investing in their autonomy to make important decisions about their lives on the other.

The conceptual tension between promoting children's rights and respecting their capacity to make decisions for themselves has important programmatic implications. Child-led marriages present development actors with ethical dilemmas about what they should do to prevent them (and whether they should prevent them to begin with). Most child marriage interventions are designed to help children increase their ability to say no to marriages forced upon them by their parents (Bessa, 2019); these interventions follow the widespread, evidence-backed narrative that many children marry against their will and are therefore unable to choose for themselves. Yet, when children themselves decide to marry, their ability to make that decision is questioned and an opposite narrative is activated, one that suggests children need to be protected until they are old enough to be able to choose.

The debates we describe above are situated within existing legal frameworks on child marriage. The Convention on the Rights of the Child does not specifically refer to child marriage, however it mentions the need to prevent violence and maltreatment of children. It states that a child becomes an adult at age 18 and mentions that children have 'evolving capacities' (United Nations General Assembly, 1989). The General Comment issued by the United Nations Committee on the Rights of the Child emphasises the need for states to legislate a minimum age of marriage, and to ensure this is the same for girls and boys. The General Comment also recognises children's 'evolving capacities' and maturity, suggesting that judicial permission may be provided for marriages below the minimum age in certain cases (UN Committee on the Rights of the Child, 2003). In this way, the Committee 'focuses on forced marriage as the problem, rather than marriage per se' (Child Rights International Network (CRIN), 2016: 19). Recent analysis suggests that assessing children's capacity may not necessarily be an objective, straightforward process, but should be done intuitively while also being rights-based (Daly, 2020). Although child marriages may occur with the approval of formal structures, child marriages may also occur informally as customary practices that are, nevertheless, recognised by the community as well as the couple and their families.

To engage with these contradictions around children's agency in marriage, we conducted secondary data analysis of two qualitative datasets from Cameroon and Somalia, and integrated them with new data collected through semi-structured interviews with practitioners working on child marriage in Cameroon and Somalia. The purpose of this article is to contribute to the debate on what 
limits (if any) the international development community should impose onto children's agency, especially when children's actions go against international standards and norms of what is "good" for children's lives. We position this article at the conceptual space of tension between child empowerment and child protection, raising questions on the meaning of agency in childhood and its implications for effective interventions.

\subsection{Academic Narratives on Children's Agency}

The literature on agency is large and varied, offering several, at times contradictory, definitions. The word itself has been 'greatly underspecified, often misused, much fetishized' (Comaroff and Comaroff, 1997: 37). In the simplest of these definitions, agency is often described as the capacity to act, to do something (Giddens, 1984). Yet, in reality, agency is not quite that simple: the decision not to act can also be an exercise of agency (Thomson, 2013). One example is the decision to remain silent to protect one's image or self-esteem (Mannell et al., 2016); another example is where action itself may result in violence, for example reporting violence may result in retaliation by a perpetrator (Aisyah and Parker, 2014). However, from an outsider's perspective, it may be difficult to know if someone is being proactively inactive or oppressed into inaction. Some commentators have argued that an act of agency must inherently include positive intentions, for instance resisting oppressive forces, such as patriarchy (Bierria, 2014; Ibrahim and Alkire, 2008; Meyers, 2016). Agency thus may be assigned to groups who have been 'emancipated' (Auchter, 2012), reinforcing neoliberal, racialised and colonial hierarchies that operate on the logic of 'saving brown women from brown men' (Spivak, 1994). The very act of classifying some acts as agency and some as not also exposes hypocrisy among scholars who claim to advocate for girls to have freedom and voice, when only some of these actions of voice or freedom are deemed acceptable to those passing down the judgment (Bay-Cheng, 2019:465).

Kabeer's (1999) definition, commonly adopted by international development practitioners, addresses the issue of action versus inaction by integrating the end goal as an essential element of agency: people exercise agency when they act in a way that helps them pursue their goals. While the concept seems sound, and appears to allow for situations where a goal might not be positive by certain standards, issues with its operationalisation emerge when trying to understand whether someone's choices are, indeed, free. Some definitions of agency indeed hinge on the idea of agency as 'free will' (Ahearn, 2001: 114; 
Dunn and Powell-Williams, 2007: 980). Aretxaga (1998) goes so far as to use the term 'choiceless decisions' to suggest that in some situations what appears on the surface to be agency may not be, due to lack of choice. In this oxymoronic framing, agency may not be agency if there are limited options available to someone; in such cases, decisions may be viewed as occurring merely for 'survival' or as a means of coping (Burnet, 2012: 107). Building on Klocker's (2007) work, which suggested girls' agency could be thin if it is exercised within a restrictive context with limited alternative options, or thick if it occurred in a context where more options are available, Murphy-Graham and Leal (2015) suggest that girls' agency to marry in Honduras varied in quality. They describe

girls' agency as 'simultaneously thin, opportunistic, accommodating, and oppositional' (25). Opportunistic agency refers to cases where girls make swift decisions to seize new opportunities; accommodating agency refers to cases where girls may adhere to expected norms; and oppositional agency involves acting in opposition to adult authority and established norms (36-40).

Judging whether someone's choice is truly free becomes even more complicated when that someone is a child. If one considers children as vulnerable humans requiring special protection (Shepler, 2014), it is difficult to know at what point they can be trusted to make life decisions automomously (Hoang and Yeoh, 2015). The literature is split between two positions: while some argue children lack the ability to pursue what is truly good for them (Noggle, 2002), others argue adulthood does not distinguish the ability to make good choices either (Vaha and Vastapuu, 2018: 228), as evidenced by the harmful roles adults may play in children's lives (Bhabha, 2006: 1532). Bordonaro (2012) explains the conundrum like this: 'how does our approach to children's agency change when their actions go against the grain of current morality, when their agency is not what it is expected to be?' (415).

\subsection{NGO and UN Narratives on Child Agency and Child Marriage}

NGO and UN narratives on child marriage emerge through research reports, technical guidance and advocacy materials. These documents position child marriage as a problem, emphasising the need to prevent child marriage by citing evidence on its negative impact on child brides. These impacts include limited voice within marriage, restricted access to economic and health services, and school dropout (International Center for Research on Women, 2005; Plan International, 2011; Save the Children, 2019; UNICEF, 2005; World Vision, 2008). Despite child marriage also being a problem in countries like the United States (McFarlane et al., 2016), NGO and UN reports focus on child marriage in lowand middle-income settings, linking the practice to poverty and culture. Often, 
perhaps due to the advocacy focus of NGO and UN documents, the tone (and visuals) around child marriage are emotive:

Picture the life of many a child bride. She is removed from her family and taken to live with a man who is rarely of her own age or choosing. Her husband and in-laws demand prompt and repeated childbearing ... She is likely to experience early and forced sexual intercourse ... She must drop out of school, stunting her intellectual growth and often isolating her from peers

World Vision UK, 2013: 3

Sahar leans on a wall and speaks from beneath a veil that conceals everything but her eyes, which glint at the mention of school and a 'beautiful past.' A tear appears, but she holds it back

Save the Children, 2019: 6

Within these narratives, children are presented as powerless against the decisions of their (especially male) family members. Subjected to 'tradition' and culture (Horii, 2020b) marriage is 'forced' upon girls, ending their participation in education and economic activity. Certainly, data on child marriage suggests children might often be forced into marriage, and that most child marriages are not child-led. As a consequence, interventions tend to be designed to encourage children to resist forced marriages (Davis et al., 2013); it is not uncommon for NGO s and UN actors to suggest that increasing girls' agency enables this challenge to child marriage (Plan International, 2011: 49; UNFPA and UNICEF, 2019: 6; World Vision UK, 2013: 37).

The language around "agency" is not confined to advocacy materials but also emerges in technical guidance for practitioners that emphasises improving girls' knowledge. For example, a rapid review of UNFPA and UNICEF life skills programmes for adolescent girls (2019) highlighted that "agency/empowerment" are often themes in toolkits and manuals. Under this topic, agency/ empowerment includes decision-making, gender-based violence, self-esteem, assertiveness and body image (16). A UNFPA (2020) technical guidance note on scaling up child marriage interventions has a pillar focused on at-risk girls 'effectively making their own informed decisions and choices regarding marriage, education, and sexual and reproductive health' through activities such as life skills and sexuality education, rights promotion and community-based behaviour change activities (1). In both these examples, girls lack knowledge that NGO s and UN actors provide; such knowledge leads to agency. 
NGO and UN narratives on child marriage often vacillate between presenting the vulnerability of girls to child marriage on the one hand, while asserting girls' agency to resist marriage through the process of empowerment on the other hand (Plan UK, 2013: 13, 49; Save the Children, 2019: 7; UNFPA and UNICEF, 2019: 6; UNICEF and International Center for Research on Women, 2017: 47). The vulnerability argument is sometimes contradictory, seeming to limit opportunities for agency: 'a young girl's wishes are typically subordinated to those of her parents and the men in her life, which virtually precludes her from resisting, much less preventing, her marriage as a child' (Plan UK, 2013: 14). However the NGO's efforts in building agency and resilience is supposed to enable girls to 'resist' child marriage (Davis et al., 2013: 49), with the result that empowered girls, 'advocated for themselves by telling their parents they had rights and did not want to be married early' (World Vision, 2019: 23). This is not dissimilar to NGO narratives about 'third world women' which have been critiqued by feminist scholars for simultaneously presenting women as victims and agents of transformation (Cornwall and Rivas, 2015: 400). In both sets of narratives, NGO s facilitate the transition to the vulnerable becoming 'agents of change' (Davis et al., 2013: 10; UNICEF and International Center for Research on Women, 2017: 47).

The NGO and UN narrative that suggests girls use agency to resist marriage aligns with neoliberal narratives focused on the power of the adolescent girl (Lloyd, 2014; Plan International Australia, 2018; UNFPA, 2011a, 2011b; World Bank, 2014). For example, a UNFPA (2015) report on adolescent pregnancy states: 'Adolescent girls are shaping humanity's present and future. Depending on their opportunities and choices, they can begin adulthood as empowered and active citizens, or become neglected, voiceless and entrenched in poverty' (4). The impetus to resist child marriage shifts to the girl. This is not to say that increasing girls' agency is the sole focus of NGO and UN interventions; indeed, there is a growing body of evidence documenting the importance of multi-layered strategies to respond to child marriage including social norms approaches, legal reforms and promoting girls' education. However, the logic of girls exercising agency to challenge marriage is a clear thread that runs through NGO and UN narratives, despite the contradictions in presenting girls as both vulnerable and agential.

We do not intend to question the fact that a significant number of children in the world today are married against their will, or the fact that they should have the possibility to resist and say no to marriages that are forced upon them. Nor do we question that child marriages, whether led by children or forced by adults, have negative health, educational and social consequences. Rather, we suggest that in cases of child-led marriages, current NGO and UN 
conceptualisations of agency may result in contradictory narratives about what it means to be a child and what it means to make choices. NGO and UN reports on child marriage solely frame the practice as forced upon children, and do not acknowledge the varied forms of child marriage, including child-led marriages. To contribute to debates on these tensions, we look at and reflect critically on two cases of child-led marriages, those of children in Cameroon and Somaliland.

\subsection{Marriage Practices in Cameroon and Somalia}

In Cameroon, while the penal codes states that the minimum legal age for marriage is 18 for girls and boys, the more recent 2019 civil codes says the age of marriage for girls is 15 and for boys is 18 (Girls Not Brides, 2018; Institut National de la Statistique (INS) and ICF International, 2020). Despite the law condemning child marriage, in 201813 per cent of women were married by age 15, 36 per cent by the time they were 18 (Institut National de la Statistique (INS) and ICF International, 2020). The ethnographic literature suggests that the continuation of the practice is linked to how marriage is understood in Cameroonian culture, which differs based on geography and ethnic group. In East Cameroon, marriage practices are 'highly fluid, flexible and negotiable' (Notermans, 2004: 8). Formal marriage and informal sexual relationships exist alongside each other for both women and men (Van der Sijpt and Notermans, 2010), so that women do not experience shame in giving birth to children from multiple relationships and marriages, and may even aspire to do so (Notermans, 2004). Recent research in the South-West of Cameroon highlights how these fluid understandings of relationships and marriage may be sustained by the spread of mobile phones and the internet: increased mobile phone use among teenagers has made it easier for private romantic liaisons, offering girls increased decision-making power in rejecting or accepting communications from boys and men in certain geographical regions (Mokake, 2015).

In Somalia, the 1975 Family Code sets the minimum age of marriage at 18 for both girls and boys, while the 2012 Constitution states that marriage can occur at the age of maturity, without defining at what age maturity occurs (OECD Development Centre, 2019). The regional authorities of Somaliland and Puntland - where the data analysed in this article were collected - have not enacted legislation on the minimum age of marriage (OECD Development Centre, 2019). In 2011, 38.1 per cent of women aged 20-49 had been married by age 18 in Somaliland, and 30.8 per cent had been married in Puntland (UNICEF and International Center for Research on Women, 2017; UNICEF Somalia and Somaliland Ministry of Planning and National Development, 2014). Community views on elopement and divorce are critical to 
understanding when and how people get married. Divorce is often common and acceptable; in Banta, which is located in Southern Somalia, one scholar reported that 'most' women end up divorcing at least once, with both men as well as women initiating divorce (Besteman, 1995: 199), pointing to women's ability to exercise agency in this domain. According to another scholar, in Southern Somalia most people marry several times (Luling and Adam, 2015: 142). Elopement is seen in Somalia as 'virtually an institution' which couples use when they cannot obtain consent or when they lack funds for a wedding (Luling and Adam, 2015: 155). Historically, elopement was particularly frequent as a form of first marriage (Lewis, 1994), albeit one that is less socially acceptable than arranged marriages (Ahmed, 2004). However, more research is needed to understand recent evolutions of elopement. More recently, elopement may be linked to peer pressure to marry early (Isse, 2017), partly heightened by the spreading access to technology that increases the visibility of peers' marriage (Kenny et al., 2019). Elopements are not necessarily a new practice in Somalia, with cases of elopements recorded as far back as the 1920s (Declich, 2016). Declich (2016) also outlines how new marriage laws implemented under Italian colonial rule differed from indigenous marriage practices and were instituted to enable colonial control of men's labour, meaning men could force women into marriage without needing the family's approval. She suggests marriages in Southern Somalia became more patriarchal and less situated within broader social relationships under these laws. The new rules also resulted in girls marrying even earlier - before puberty as men were given more freedom to choose brides.

This study sought to explore how practitioners and communities in Somalia and Cameroon understand children's agency with respect to marriage, including how marriage practices have changed over time. The objectives were to identify how communities make decisions about marriage, to explore how practitioners perceive children's agency, and to understand changes in child marriage over time. We explored children's agency in marriage in these two settings (Cameroon and Somaliland/Puntland) combining both community members' and practitioners' voices, using the methods detailed in the following section.

\section{Methods}

To conduct this research, a range of methods were used. In Cameroon and Somaliland/Puntland, focus group discussions (FGDs) and key informant interviews (KII s) were carried out in two separate studies. In 2019-202O, we 
conducted KII s using Skype with practitioners working on child marriage in both countries to further explore the concept of child-led marriage.

\subsection{Participants}

The Cameroon data was collected in four villages. In total, 16 FGD s were held reaching 8 o participants, as well as 27 key informant interviews (21 men and 6 women). A more detailed description of the methods for this study is available elsewhere (Cislaghi et al., 2019). In Somalia, data was collected from four communities - two in Somaliland and two in Puntland. In total, 15 FGD s were held, reaching 120 participants, alongside 36 key informant interviews (24 women, 12 men). The methods for this study are detailed elsewhere (Kenny et al., 2019). For both the study in Cameroon and Somaliland/Puntland, the original focus of research was child marriage more broadly; however in the course of both studies, the topic of child-led marriages and agency emerged. For the purposes of this paper, we focused our analysis on the agency-related themes. In addition to conducting a secondary data analysis of the data collected in Cameroon and Somaliland/Puntland, we held eight Skype interviews with practitioners working on child marriage in these two countries. These practitioners were selected purposively, from existing networks held by the authors and other colleagues, and expanded through snowballing techniques. Four of these practitioners (all but one of the Somalia interviewees) were international staff, while the remainder were members of national teams. Of these eight participants, four worked for international NGO s, two worked for local NGO s and two worked for UN agencies. Two of the participants for Somalia were involved in the original research on child marriage in Somaliland/Puntland, however any statements made about those research findings regarding child-led marriages were not included in the analysis, to avoid overly weighting this data. Table 1 below describes all the datasets used in this article.

\subsection{Data Collection and Analysis}

In both countries, local interviewers conducted and audio-recorded the FGD s and KII s. Informed consent was obtained from all participants. For Skype KII s with practitioners, informed consent was obtained by the first author, who conducted all the interviews, taking notes only. Both the original datasets and practitioner KII s explored the reasons for child marriage and decision-making on marriage. Practitioner KII s further explored the practice of child-led marriages, the conceptualisation of agency and choice, and the role of NGO and $\mathrm{UN}$ activities in behaviour change.

In both Cameroon and Somaliland/Puntland, two local translators transcribed and translated audio recordings into English. Codes were jointly 
TABLE 1 Data used as part of the study

\begin{tabular}{lllllr}
\hline Dataset & Country & Method & Women & Men & Total \\
\hline Previously collected & Cameroon & FGD s & 40 & 40 & 80 \\
& & KII S & 6 & 21 & 27 \\
& Somalia & FGD s & (mixed) & (mixed) & 120 \\
& & KII s & 24 & 12 & 36 \\
New data & Cameroon & PKII S & 1 & 2 & 3 \\
& Somalia & PKII S & 2 & 3 & 5 \\
\hline
\end{tabular}

Note

FGD s Focus Group Discussions

KII s Key Informant Interviews

PKII S Key Informant Interviews with Practitioners

developed by the two research teams. For this article, all the original FGD and KII transcripts were read by the first author. Rather than using existing codes, new codes were developed to focus on issues of agency, decision-making and child-led marriages. Prior to the practitioner KII s, the FGD and KII data from Cameroon and Somaliland/Puntland were grouped into key agency-related themes. Based on these themes, the interview guide for the practitioner KII s was developed. The practitioner KII data was then inserted into these agency-related themes. However, there were some themes that only emerged from practitioner KII s and not the Cameroon and Somaliland/Puntland datasets.

\subsection{Ethical Approval}

In both Cameroon and Somaliland/Puntland, local interviewers were trained on consent, confidentiality and skills for conducting FGD s and KII s. For the Cameroon data, ethical approval was obtained by the University of California San Diego (Ethics approval number: 170489S, 4 April 2017) and by the Cameroonian Ministry of Health in 2017. For the Somaliland/Puntland data, ethical approval was obtained by the London School of Hygiene and Tropical Medicine (Ethics approval number 14397, 3 October 2017) and by the Ministry of Labor and Social Affairs in 2017. The ethical approvals for this current study, including review of the existing Cameroon and Somaliland/Puntland datasets and conducting Skype interviews with practitioners, were obtained from the London School of Hygiene and Tropical Medicine (Ethics approval number: 17892, 22 November 2019). 
In our investigation, we looked at the meaning and value community members and practitioners assigned to children's agency, especially regarding marriage-related choices. Comparing and contrasting their views, we identified four themes which have implications for NGo programming, as well as for how child marriage is framed in international and national legal instruments. The first theme relates to the emergence of child-led marriage as a growing practice in these countries. The second looks at the temporary nature of childled marriages, including the practice of divorce following child-led marriage. The third presents findings related to the belief that children are too young to exercise agency and ontologically incapable of deciding to get married. The fourth and final theme questions whether children's decisions can be considered free as they may face a restricted set of options, lack of information on the consequences of their decisions and limited knowledge of their rights.

\subsection{Child-Led Marriages as an Increasing Practice}

Community members from both countries said child-led marriages are an increasing phenomenon, growing in recent years. A man in Cameroon, for instance, said, 'Today things have changed. A boy and a girl meet. They love each other, that's all. Their parents will [only] arrange the procedures of marriage' (male FGD, 11-FN_MA, Maga, Cameroon). A Somali woman reflected on how child-marriages have not only increased, but are a sign that parents are being ousted from any marriage-related decisions: 'In the past a girl had no choice ... her father made all decisions regarding her marriage... But now these young boys and girls make all the decisions about their marriage and never involve parents' (female FGD, Hargeisa, o1, Somalia). In contrast to community perceptions that children are choosing to marry, all but two practitioners (who had themselves been involved in research that found evidence of child-led marriages in Somalia) felt that child-led marriages were not that common, tending to prefer emphasising that marriage decisions are exclusively taken by adults. A few practitioners specifically referred to child-led marriages as 'rare' and 'anecdotal'. In the majority of cases, practitioners reacted to the idea of child-led marriages by discussing issues around children being unable to consent, or children choosing to marry due to lack of choice. Practitioners described a patriarchal decision-making system, where the decision to marry a daughter off is mostly made by fathers or other male relatives, with female family members (mothers, mothers-in-law and grandmothers) sometimes involved but not making the final decision. A few practitioners working in Somalia were aware of children's desire to marry, but one believed children's 
wishes do not result in marriage because parents tend to refuse, preferring them to continue their education. Practitioners in Cameroon acknowledged that there were cases where children decided to marry, and that parents in some communities supported the decision while others were unhappy about their children's choices.

Community members and practitioners mentioned two reasons why child-led marriages had become more common in recent years. First, access to the internet and smartphones had narrowed the romantic space; boys and girls were now able to chat with the opposite sex without their parents knowing. A woman from Somalia, for instance, remarked,

In the past the eloping couple were grown-up people who saw each other and then ... escaped together. But now they chat on the phone and may not even see each other. When they finish their chat on the phone, they decide to elope

Female KII, 13_BR, Somalia

Another woman from Somalia commented, 'They get to know each other on this internet ... two people who may have never met' (female KII, Hargeisa 11, Somalia). As an example from Cameroon, one man commented, 'But today, girls of 12 years have telephones [they use to talk to boys] and parents don't say anything' (male FGD, ES-NG, Cameroon). Smartphones and access to social media may also result in projecting a socially appropriate image of child marriage that could induce children to emulate their peers to receive the same approval: 'They learnt this from the films and these other stuffs that they are watching' (female KII, Hargeisa 12, Somalia); 'They see a lot of movies from the TV s especially those that were translated into Somali, where there are many inappropriate practices talking about love, elopement' (female, mixed FGD, Buroa 4, Somalia); 'And now with your stimulating sexual movie business ... it educates the kids' (men's FGD, 7-ES_DO, Cameroon). The fact that girls and boys may form relationships on the internet was mentioned in multiple KII $\mathrm{s}$ and FGD s in Somalia and Cameroon, however practitioners did not mention this.

As well as smartphones and the internet, community members mentioned that adolescents saw schools as creating a space far from their parents' eyes where they could meet and get to know each other. The recent emergence of child-led marriages was attributed to more children attending school, which has increased socialisation between students and sometimes resulted in girls getting pregnant (female, $\mathrm{NGO}$, Cameroon). A man from Somalia also reflected on this: 
While he [the boy] is in school, he gets to know about the girls in the school and they chat [court] ... They simply ask themselves, 'Shouldn't we get married?' without thinking about their future and the importance of marriage. Then they elope

Male, mixed FGD, FGD 2, Somalia

School attendance may also foster adolescents' desires to emulate their peers: 'They copy each other' (female KII, Hargesia, Somalia). Another woman, also from Somalia, said, 'When they see two other dating couples or two who are married ... they elope without the knowledge of their parents' (female, mixed FGD, Buroa 2, Somalia). While peer emulation was mentioned in Somalia, community members in Cameroon did not note this phenomenon. One NGO practitioner who worked in Cameroon, however, said that adolescents wanted the social and material benefits from marriage: 'They see their friends getting married. When they marry, there are benefits - gifts. They see that and think it's something they can copy'.

In addition to the two reasons mentioned above, participants in Somalia said that child-led marriages were also motivated by parents not paying enough attention to their children: 'Now there is a lot of negligence and irresponsibility from the fathers ... When the father is busy chewing khat the whole day and does not spend time with his sons and teach them good disciplines and morals ... [the son elopes]' (female KII, Lasanood 16, Somalia). Another reflected: '[I]f the parent chats and advises the children ... that would change them' (female KII, Hargeisa, 12, Somalia). While mentions of child-led marriages were limited among practitioners, some agreed that child-led marriages were increasing because of parents' distance from their children. A practitioner working in Somalia specifically mentioned that parents 'were not aware of what children are doing' because the conflict had increasingly meant both parents left home to earn money. Consequently, children had 'more freedom to do what they want with no repercussions' (male, $\mathrm{NGO}$, Somalia). The reduction of time that parents spent with children also resulted in a reduction of closeness: 'In the past, children shared any thoughts to their family ... But now, they won't share anything with their parents, if they are going to get married, they won't tell anybody' (male KII, Buroa, Somalia). Practitioners also mentioned the secrecy associated with elopement: 'No child will tell you they are eloping' (male, NGO, Somalia). In Cameroon, community members and practitioners did not directly blame parents for children eloping, however a female UN staff member from Cameroon suggested that child-led marriages may be due to how parents speak about marriage in front of children. 


\subsection{The Temporary Nature of Child-Led Marriages}

Both community members and practitioners discussed the temporary nature of child-led marriages, with references to multiple marriages as well as the idea that child-led marriages may end early with divorce. One woman, for instance, told the story of her son, who had eloped without telling the family. His father approved of this decision, describing it as 'smart' to let the son continue with this girl, so they were married and she gave birth to his child. In an FGD, the mother then continued to explain how her son then eloped with another girl: 'Then I got very angry ... I told myself, let his father handle this. He is the one who was saying he is smart when he brought the first one ...' (female, mixed FGD, Buroa 3, Somalia). Another woman in Somalia reflected on the shortterm approach to marriage: 'In fact, nowadays young couple do not marry for a good future together. They don't agree on any pre-conditions ... It does not last long' (female KII, O1_HG, Somalia). Communities in Cameroon also reflected on this: 'There are girls who get married and then divorce later' (male FGD, 1-ES_NG, Ngoura, Cameroon); 'Now you can see the child of your uncle or aunt and ask her hand in marriage. If she was married and later on divorced, you can ask her hand in marriage if she accepts' (male KII, 1-ES-NG, Cameroon).

A practitioner working in Somalia remarked that child-led marriages usually are 'short-lived', due to the boy being unable to sustain the expense of maintaining a family (male, NGO, Somalia). Another, who said that children 'find marriage difficult so they divorce' (female, NGO, Somalia), suggested that young girls are not prepared for household responsibilities that they are expected to take on, which also eventually leads to divorce. The few practitioners who discussed child-led marriages in more depth said that communities saw divorce following a child-led marriage in ambivalent terms: marriage breakups were viewed by some as positive events for a girl, offering the opportunity to be freed from a difficult marriage, while others believe the role of a female is to be married, so she should remain in the marriage. An example was shared of a girl who was abandoned by her family. This girl did not have other support, so she married an old man, with the plan 'to leave to find a better situation' (female, UN, Cameroon) - illustrating the temporary nature of marriage. In community and practitioner data, the fact that these marriages might be temporary was not referenced as evidence for why children should not marry.

\subsection{Children are Too Young to Make Important Choices about Getting Married}

The idea that children are too young to decide to marry was a dominant practitioner narrative, however was not mentioned by communities in 
Cameroon or Somalia. Many practitioners said children are simply not old enough to consent to marriage. One used a metaphor when he suggested children, in recent times 'have gained agency [to get married], but it's like having access to a car before being eligible for a driver's license' (male, NGO, Somalia). Several practitioners thought the argument to be self-evident: that children are not yet able to make life-changing decisions was demonstrated by the fact they chose a negative outcome (their marriage). This is a dangerously fragile argument, on which we will return in the discussion section. Not only did practitioners think children were ontologically incapable of making key decisions, they also thought children did not possess information on the consequences of the decision to marry. They suggested full information to be a critical aspect of taking free decisions. For instance, one, who worked in Somalia, said: 'It's hard to exercise agency if you don't have the full information' (male, UN, Somalia). Another practitioner, who worked in Cameroon, said that child marriage was a 'common practice that is quite accepted because people don't know their rights', inferring that not knowing about rights allows child marriage to continue. Later, however, she commented, 'Even if they [girls] know their rights, what can they do if they face it [child marriage]?'

While practitioners labelled children's decisions to marry as non-decisions (thinking real decisions cannot be made at a young age), community members in Cameroon and Somalia did not question whether or not children were able to make similar decisions: they knew several children had made decisions. Many community members, including caregivers, provided descriptions of children deciding to get married despite their parents' opinions:

[T] he world has changed. Marriages are difficult. When you even propose a husband to your daughter, she will tell you that she does not love him

Male KII, 17-GN-MA, Cameroon

Any type of girl, if my son expresses his wish, I cannot oppose his choice Male FGD, 1-ES_NG, Ngoura, Cameroon

There are still some families that respect the decision of their children Male FGD, 5-ES_Do, Maka, Cameroon

In the past two adult people used to get married ... But, now the young people are escaping together and hiding off from the parents and when they escape the parents formalise it

Female KII, 15 BR, Buroa, Somalia 
In the past girls had no choice ... But now these young boys and girls make all the decisions about their marriage on their own behalf and never involve parents ... [N] owadays young people don't listen and accept their parents. Now my two young sons never consulted me when they were getting married

Female KII, Hargeisa 01, Somalia

The examples above illustrate that while practitioners questioned if children could make decisions at all due to their age, community members did not engage in debates about whether decisions made by children were decisions; they merely described the decisions children had made about marriage. However, it is important to note that community members were not directly asked about how they viewed children's decision-making. Practitioners, perhaps more familiar with debates on age of consent and marriage laws, tended to focus on the age of a child negating capacity to decide. In some examples from community members, there was a sense that the decisions of children left parents with no choice but to acquiesce to the marriages their children had chosen. One man in Somalia, for instance, said that when his son eloped, he and his wife initially said no to the marriage, but the boy and the girl 'threatened to burn down themselves [commit suicide] if their marriage is not accepted' (male FGD, 6, Erigabo, Somalia). This man then felt he had no choice: 'I then took some money and came to her family and asked for her hand and we married them off together'. A man in Cameroon also explained: 'While you think that your son is still young, he is going out with girls. One day he comes and says, "Papa, I want to get married". He gave his father no choice but to accept' (male FGD, 11-FN_MA, Maga, Cameroon).

There were exceptions to the idea that children might marry irrespective of their parents' desires, with some community members suggesting that a girl with "good conduct" will obey whatever her parents say instead of pushing for her own interests, and that their children 'don't oppose their parents' (male FGD, 11-FN_MA, Maga, Cameroon). However, the community accounts in general show much more willingness to recognise children are involved in decisions regarding their marriages, compared to practitioners, who suggested this was more exceptional and that male family members in particular made marriage decisions.

\subsection{Children Only Choose Marriage because it's the "Best" Option Available to Them}

While some practitioners, as mentioned above, suggested children are not aware of the decisions they are making, others suggested their marriage- 
related decisions are relatively choiceless, made within an extremely limited set of options. For example, in some areas of Cameroon, practitioners said girls were having relationships with armed groups 'to be protected, to get money from these actors, [so that they can] take care of their families' (male, NGo, Cameroon). One practitioner in Somalia also agreed that a girl would get married because she thinks 'she is helping her family when she marries' (female, NGO, Somalia). Because girls married for material benefits, practitioners suggested, they were not really exercising agency: 'It's not by choice - it's for survival', said a male practitioner from Cameroon.

Other practitioners suggested children were practically coerced into choosing marriage:

Sometimes children can be obliged. Even if she knows "this is not good for me", but then "because I have no one to care for me" ... They are not giving her food. She has no other way. Maybe [she thinks] "A husband can take care of me, I can go to school if he accepts"

Female, un, Cameroon

Generally speaking, practitioners questioned that marriage could be the best option for a child, and suggested digging behind children's reasons to understand why they would make a decision that was against their interests. One, for instance, said that -

Where a girl wants to marry' we should ask ourselves: "Why? What has happened?" Maybe she has been indoctrinated to believe it will bring economic benefit, therefore we cannot consider her decision to marry is one that is free. It is coerced

Male, NGO, Cameroon

We found it interesting that practitioners did not accept that children might simply wish to get married, and instead tried to uncover the system of oppression resulting in their marriage.

The table below summarises the key themes from global grey literature, practitioner interviews and community interviews. In the next section, we discuss the implications of these four themes. 


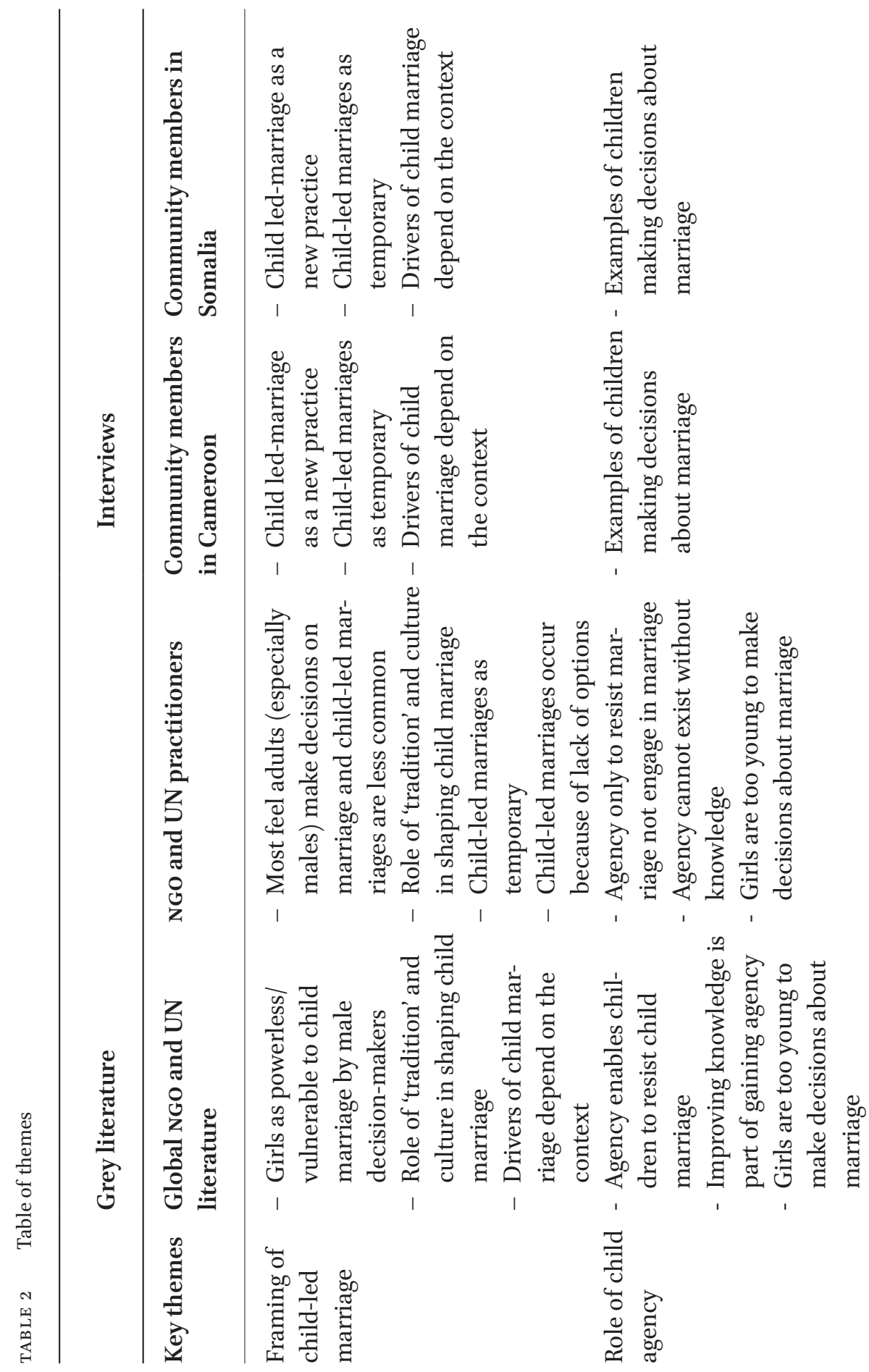




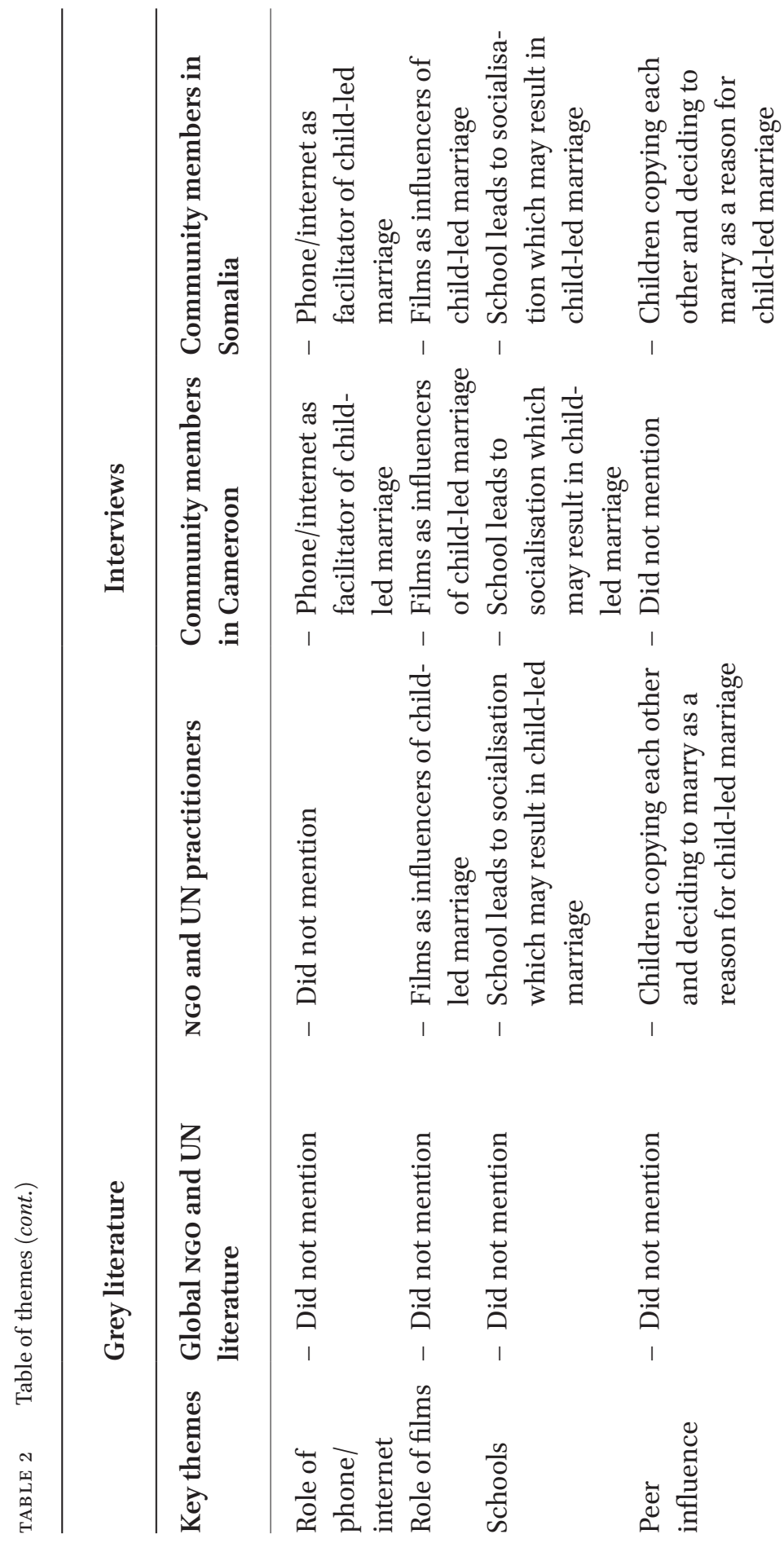




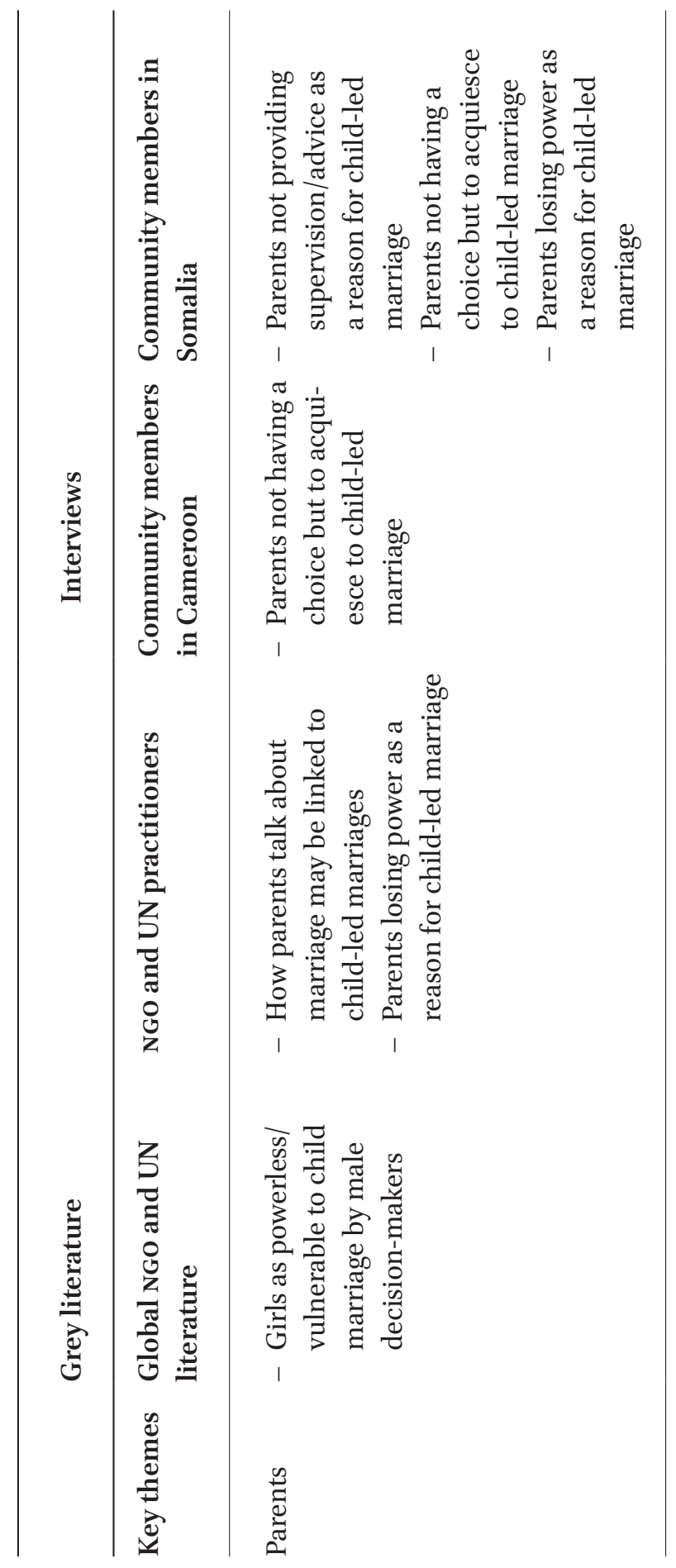


In comparing practitioner and community narratives on children's agency, we find that global NGO and UN (grey) literature on child marriage as well as practitioner interviews are aligned in their focus on child marriage as a traditional, cultural practice forced upon girls by largely male relatives. Globally, as well as specifically in Cameroon and Somalia, there is no data on the proportion of child marriages which are led by children, so this remains a research gap. It is also unclear if child-led marriages are largely occurring through formal structures, or informally, which may be a relevant focus for future research. Additionally, future research may find it useful to explore if it is girls or boys who are initiating these marriages, to understand the gendered dimensions of agency within child-led marriages. More research is also needed to understand the positive and negative outcomes of child-led marriages.

The findings indicate that practitioners were less likely to identify childled marriage as a common issue compared to communities in Cameroon and Somalia, preferring to emphasise the narrative about adults making decisions about marriage for children. It is unclear if the reticence to acknowledge that children may decide to marry is because of not being aware of this particular articulation of child marriage, having a fixed idea of parental (especially male) decision-making on marriage that positions girls as powerless, or simply due to the conceptual dissonance that children are too young to consent which means there is no decision - or a combination of these factors. Indeed, grey literature and practitioners emphasise that children exercise agency only to defy a forced marriage, that knowledge leads to agency, and that any "decisions" children make about marriage do not count because they are too young and lack information. While communities in Cameroon and Somalia provided examples of children making decisions about marriage, they did not pass judgment on whether these decisions were positive or negative, or if children were capable of such decisions, beyond some caregivers indicating their lack of choice in the marriage decisions of their children. Our research findings raise questions about what agency means and how it should be defined when it comes to children exercising agency. More broadly, these findings also interrogate the idea that a person with agency will always make "good" decisions, pointing to bigger questions for NGO s and policy-makers: who decides what a good decision is, and what is expected of the "empowered"?

The findings of this research also highlight that practitioners appear to design interventions informed by a specific discourse around children's agency. This discourse takes two main forms. First, the practitioners we interviewed believed that marrying for the reason of survival cannot be considered 
an expression of children's agency. In the example of girls engaging in relationships with armed actors, this act is written off because it is for survival. Many disagree; for instance, Thomson (2013) argued that actions taken for daily survival are strategic decisions - assertions of power and agency. Similarly, Denov et al. (2007) suggest that however negative the outcome, children may still be exercising agency. We suggest that it is complex for an outsider to judge when someone is making a truly free choice; even under a narrow conceptualisation of agency, it is challenging to determine whether agency exists or not. That is, behavioural outcomes aligning with what interventions hoped to achieve (e.g. reduction in child marriages) are not necessarily signs of children making free choices. If actions taken in a limited set of options are non-decisions, it seems complex to evaluate which actions practitioners can consider free. Judging which actions are carried out as a result of agency and which are not has consequences and risks promoting the idea that an intervention is only successful when children are doing what practitioners think they should do - reflecting broader challenges in top-down approaches to interventions. Narrowly framing outcomes in this way negates actions taken when children merely do what they can, navigating (as everyone does) a reality that constrains their options.

Secondly, the practitioners who participated in this research placed limits on children's ability to exercise agency regarding marriage, contradicting how communities describe children making decisions about marriage. The fact that practitioners were more comfortable in attributing the practice of child marriage to oppressive male decision-makers than children, suggests that practitioners may subscribe to a narrow idea of children's agency. Most practitioners preferred to cite tradition, culture and the role of parents in determining a child's future when discussing child-led marriages. In both the Cameroon and Somalia data, community members reflected on children's decisions to resist planned marriages, on children's decisions about a future spouse, and on children's decisions to themselves marry - contrasting with practitioner narratives that children cannot make decisions. Community members did not necessarily indicate that they were happy about children making their own decisions about marriage, but appeared more comfortable in simply being able to recognise a decision had been made. Practitioners, in contrast, referred to coercion and survival in describing such descriptions - writing off the decisions. This suggests that there is a mismatch in worldview on children's ability to make decisions. When viewed alongside the NGO messaging related to children being expected to flee marriage due to agency, it also emerges that grey literature and practitioner narratives may at times be selective. Within NGO reports, for example, agency is appropriated to suit whatever the narrative may be, and children's agency is only possible when linked to a "positive" outcome - itself 
difficult to define. Practitioners also described agency in terms of it resulting in a positive outcome, but it was unclear how such determinations of the positive are made. It was certainly not positive in terms of what children deemed positive - because children do not know what is best for them. Instead, it appeared from practitioner interviews that the judgment of the positive or the "good" was done by an outsider. While some scholars critique the notion that agency is by nature transformative, or an act of resistance (Ahearn, 2001; Meyers, 2016), this narrative remains pervasive in reports issued by NGO s. This framing of agency has important implications. It means that the expectations on those with agency (and by extension, those who have been "empowered") are onerous. Their actions are supposed to be predictable and in their best interests, and apparently are not agency when the choices are limited or when they do not have knowledge about the dangers of the outcomes, in this case child marriage. This problematic way of thinking about agency results in the contradictions outlined above, in the appropriation of agency to suit dominant narratives, and in a limited way of thinking about human behaviour.

Thirdly, the connection between having knowledge about the dangers of child marriage and exercising agency also emerges as a critical tension from the findings. Practitioners have diverse opinions about the extent to which knowledge about an issue can stop it from being practised. The comments about children not having the cognitive ability to decide about child marriage, and needing information to make informed choices about marriage, reflect that knowledge is positioned as influencing a decision to marry. Some practitioners, however, noted the limits of this narrow framing of child marriage, acknowledging that information is not enough to stop the practice. Importantly, the link between knowledge and agency means that girls who do marry as children may be viewed as past the point of intervention. When conceptualisations of agency only focus on the idea of agency as resistance, the agential potential of girls who marry may be neglected. In fact, it may be that if marriage is seen as less long-term, and if divorce is viewed as more acceptable, it may be possible for girls to leave marriage - and this could be a potential way of expanding girls' agency. However, it is worth noting that the age of the girl, her knowledge of legal/Islamic processes required for divorce and access to legal assistance may limit the exercise of agency. Child marriage may not be the end of a girl's economic and education options; indeed, marriage may be a way for a girl to continue her education if the husband agrees, as was stated by one practitioner. It is worth noting here that school dropout is influenced by multiple factors apart from child marriage, including financial cost, distance, competing economic opportunities and household division of labour, making it difficult always to attribute dropout to child marriage alone. Girls who marry 
may still attend school, especially when effort is made to include married girls, including through varying the timing of classes so that they occur after girls complete their household tasks (El Nagar et al., 2017: 52). There may be opportunities for NGO s wanting to engage more in the "response" rather than solely "prevention" of child marriage, by targeting already-married girls and boys more intentionally, instead of automatically assuming that their opportunities, status and treatment in a child marriage are negative and always limit agency, as the grey literature suggests. Additionally, alongside other strategies, interventions could directly engage with community norms on divorce and seek opportunities to leverage these.

\section{6}

\section{Conclusion}

The findings of this study offer the opportunity to examine the tension between child protection and empowering children to make decisions. This study suggests the need to increase conceptual clarity on the meaning of children's agency for effective development interventions. Children's agency is perceived as only possible when it results in "positive" outcomes, which has resulted in child marriage being analysed solely as being forced by adults upon children, or being initiated by children who lack information or alternative options. Viewing children's agency in this light has resulted in narrow interventions which suggest that if children and adults are given information about child marriage, they will not practise it. Our findings challenge this conceptualisation of child marriage, suggesting that greater nuance is needed in designing child marriage interventions, recognising that at times, marriage may be an expression of the agency of a child. Understanding child marriage from the perspective of child agency creates opportunities for other kinds of interventions, including those supporting girls and boys after marriage, providing legal advice (e.g. on divorce) and educational opportunities, and tackling prevention activities through the lens of children's decision-making rather than adults forcing decisions upon children.

We suggest that the ideologies on agency discussed in this article reflect the need for more work on conceptualising children's agency (and indeed, agency more broadly). Expanding the definition of agency removes the value judgments that have been quite explicitly present in NGO narratives - and some academic work - on agency. A broader definition allows agency to be viewed through a more neutral lens that is not constrained by requiring the rejection of systemic injustice, but is situated in the intentions and manoeuvrings (however short-term, or however not "good") of the individual. We suggest that 
understanding children's agency more broadly, without the requirement of a "positive" outcome eventuating from decisions, allows a broader analysis of the varied ways in which child marriage may occur. This kind of approach may enable NGO s to think differently about the post-marriage stage of girls and boys, allowing potential for the agency of married children to be expanded. Shifting from an outside-in, outcome-driven analysis of agency to an approach that centres the intentions of those exercising agency may be more productive.

By unravelling and challenging common narratives on children's agency, this article has exposed contradictions in how child agency is conceptualised. It urges development NGO s, UN actors and policy-makers critically to re-evaluate the use of the term "agency", which may involve also re-conceptualising what it means to design interventions for the "good" of communities and what it means to accept community choices, whether we perceive them as positive or negative.

\section{References}

Ahearn, L.M. "Language and Agency", Annual Review of Anthropology 2001 (30), 109-37. Ahmed, S.M., "Traditions of Marriage and the Household", in J. Gardner and J. El-Bushra (eds.), Somalia - the Untold Story: The War through the Eyes of Somali Women, (London: Pluto Press, 2004), 51-68.

Aisyah, S. and L. Parker, "Problematic Conjugations: Women's Agency, Marriage and Domestic Violence in Indonesia", Asian Studies Review 2014 (38(2)), 205-23.

Aretxaga, B., Shattering Silence: Women, Nationalism, and Political Subjectivity in Northern Ireland (Princeton: Princeton University Press, 1998).

Arthur, M. et al., "Child Marriage Laws around the World: Minimum Marriage Age, Legal Exceptions, and Gender Disparities", Journal of Women, Politics \& Policy 2018 $(39(1)), 5^{1-74}$.

Auchter, J., (2012) "Gendering Terror", International Feminist Journal of Politics 2012 (14(1)), 121-39.

Bajracharya, A., S. Psaki and M. Sadiq, Child marriage, adolescent pregnancy and school dropout in South Asia (2019).

Bantebya, G.K., Muhanguzi, F.K. and Watson, C., Adolescent girls in the balance: Changes and continuity in social norms and practices around marriage and education in Uganda (2014).

Bay-Cheng, L.Y., "Agency Is Everywhere, but Agency Is Not Enough: A Conceptual Analysis of Young Women's Sexual Agency”, The Journal of Sex Research 2019 (56(45)), 462-74. 
Bessa, T., "Informed Powerlessness: Child Marriage Interventions and Third World Girlhood Discourses", Third World Quarterly 2019 (40(11)), 1941-56.

Besteman, C., "Polygyny, Women's Land Tenure, and the 'Mother-Son Partnership' in Southern Somalia", Journal of Anthropological Research 1995 (51(3)), 193-213.

Bhabha, J., The Child: What Sort of Human?, Source: PMLA (vol. 121, 2006).

Bierria, A., "Missing in Action: Violence, Power, and Discerning Agency", Hypatia 2014 (29(1)), 129-45.

Bordonaro, L.I., "Agency Does Not Mean Freedom Cape Verdean Street Children and the Politics of Children's Agency", Children's Geographies 2012 (10(4)), 413-26.

Burnet, J.E., "Situating Sexual Violence in Rwanda (1990-2001): Sexual Agency, Sexual Consent, and the Political Economy of War", African Studies Review (55(2)), 97-118.

Child Rights International Network (CRIN) (2016), Age is arbitrary: setting minimum ages.

Cislaghi, B. and Bhattacharjee, P., Honour and prestige: The influence of social norms on violence against women and girls in Karnataka, South India (2017).

Cislaghi, B., G. Mackie, G., Nkwi, P. and Shakya, H., "Social Norms and Child Marriage in Cameroon: An Application of the Theory of Normative Spectrum", Global Public Health 2019 (14(10)), 1479-94.

Comaroff, J.L. and Comaroff J., Of Revelation and Revolution, Volume II, The Dialectics of Modernity on a South African Frontier (Chicago: University of Chicago Press, 1997).

Cornwall, A. and Rivas, A.M., "From 'Gender Equality and Women's Empowerment' to Global Justice: Reclaiming a Transformative Agenda Gender and Development", Third World Quarterly 2015 (36(2)), 396-415.

Daly, A., "Assessing Children's Capacity", The International Journal of Children's Rights $2020(28(3)), 471-99$.

Davis, A., Postles, C. and Rosa, G., A girl's right to say no to marriage: Working to end child marriage and keep girls in school (2013).

de Groot, R., Kuunyem, M.Y. and Palermo, T., "Child Marriage and Associated Outcomes in Northern Ghana: A Cross-Sectional Study", BMC Public Health 2018 (18(285)), 1-12.

Dean, L. et al., (2019) "He Is Suitable for Her, of Course He Is Our Relative: A Qualitative Exploration of the Drivers and Implications of Child Marriage in Gezira State, Sudan", BMJ Global Health 2019 (4), 1-12.

Declich, F., "Italian Wedding Memory and Trauma: Sexual Policies in Southern Somalia, 1910-1945", in B.N. Lawrance et al.(eds.), Marriage by Force? Contestation over Consent and Coercion in Africa (Ohio: Ohio University Press, 2016).

Denov, M. and Gervais, C., "Negotiating (in)Security: Agency, Resistance, and Resourcefulness among Girls Formerly Associated with Sierra Leone's Revolutionary United Front", Signs 2007 (32(4)), 885-910. 
Dunn, J.L. and Powell-Williams, M., “Everybody Makes Choices': Victim Advocates and the Social Construction of Battered Women's Victimization and Agency", Violence Against Women 2007 13(10), 977-1001.

El Nagar, S., S. Bamkar, S. and Tønnessen, L., Girls, Child Marriage, and Education in Red Sea State, Sudan: Perspectives on Girls' Freedom to Choose (2017).

Erulkar, A., "Early Marriage, Marital Relations and Intimate Partner Violence in Ethiopia", International Perspectives on Sexual and Reproductive Health 2013 (39(1)), 6-13.

Erulkar, A. and Muthengi, E., "Evaluation of Berhane Hewan: A Program to Delay Child Marriage in Rural Ethiopia”, International Perspectives on Sexual and Reproductive Health 2009 (35(1)), 6-14.

Gage, A.J., "Association of Child Marriage with Suicidal Thoughts and Attempts among Adolescent Girls in Ethiopia", Journal of Adolescent Health 2013 (52), 654-6.

Gastón, C.M., Misunas, C. and Cappa, C., "Child Marriage among Boys: A Global Overview of Available Data", Vulnerable Children and Youth Studies 2019 (14(3)), 219-28.

Giddens, A., The Construction of Society (Berkeley: University of California Press, 1984).

Girls Not Brides, "Cameroon" (2018): https://www.girlsnotbrides.org/child-marriage/ cameroon/.

Hoang, L.A. and Yeoh, B.S., “Children's agency and its contradictions in the context of transnational labour migration from Vietnam”, Global Networks, 2015 (15(2)), 180-97.

Horii, H., "Walking a Thin Line: Taking Children's Decision to Marry Seriously?", Childhood 2020a (27(2)), 254-270.

Horii, H., "A Blind Spot in International Human Rights Framework: A Space between Tradition and Modernity within the Child Marriage Discourse", The International Journal of Human Rights 2O2Ob (24(8)), 1057-79.

Ibrahim, S. and S. Alkire, S., "Agency and Empowerment: A Proposal for Internationally Comparable Indicators", OPHI Working Paper (2008).

Institut National de la Statistique (INS) and ICF International, Enquête Démographique et de Santé du Cameroun 2018 (2020).

International Center for Research on Women, Too young to Wed: Education \&amp; Action Toward Ending Child Marriage (2005).

Isse, N.J., Causes and Effects of Early Marriage in Garowe District, Puntland State of Somalia (2017).

Kabeer, N., "Resources, Agency, Achievements: Reflections on the Measurement of Women's Empowerment", Development and Change 1999 (30), 435-64.

Kalamar, A.M., Lee-Rife, S. and Hindin, M.J., "Interventions to Prevent Child Marriage among Young People in Low- and Middle-Income Countries: A Systematic Review 
of the Published and Gray Literature", Journal of Adolescent Health 2016 (59(3)), S16-21.

Kenny, L., Koshin, H., Sulaiman, M. and Cislaghi, B., "Adolescent-Led Marriage in Somaliland and Putland: A Surprising Interaction of Agency and Social Norms", Journal of Adolescence 2019 (72), 101-11.

Kidman, R., "Child Marriage and Intimate Partner Violence: A Comparative Study of 34 Countries", International Journal of Epidemiology 2017 (46(2)), 662-75.

Klocker, N., “An Example of 'Thin' Agency: Child Domestic Workers in Tanzania”, in R. Panelli et al. (eds.), Global Perspectives on Rural Childhood and Youth: Young Rural Lives (New York: Routledge, 2007).

Lewis, I.M., Blood and Bone: The Call of Kinship in Somali Society (Lawrenceville: Red Sea Press, 1994).

Lloyd, C., New lessons: the power of educating adolescent girls (2014).

Luling, V. and Adam, A.S., "Continuities and Changes: Marriage in Southern Somalia and the Diaspora", Northeast African Studies (2015).

Malhotra, A., Warner, A., McGonagle, A. and Lee-Rife, S., Solutions to end child marriage: what the evidence shows (2011).

Mannell, J., Jackson, S. and Umutoni, A., "Women's Responses to Intimate Partner Violence in Rwanda: Rethinking Agency in Constrained Social Contexts", Global Public Health 2016 (11(1-2)), 65-81.

McDougal, L. et al., "Beyond the Statistic: Exploring the Process of Early Marriage Decision-Making Using Qualitative Findings from Ethiopia and India", BMC Women's Health 2018 (18(144)), 1-16.

McFarlane, J., Nava, A., Gilroy, H. and Maddoux, J., "Child Brides, Forced Marriage, and Partner Violence in America Tip of an Iceberg Revealed", Obstetrics \& Gynecology $2016(127(4))$, 706-13.

Mehra, D., Sarkar, A., Sreenath, P., Behera J. and S. Mehra, S., "Effectiveness of a Community Based Intervention to Delay Early Marriage, Early Pregnancy and Improve School Retention among Adolescents in India", BMC Public Health 2018 $(18(732)), 1-13$.

Meyers, D.T., "Surviving Evils and the Problem of Agency: An Essay Inspired by the Word of Claudia Card", Metaphilosophy 2016 (47(4-5)), 539-57.

Mokake, F.M., "Teenage Girls, Cell Phones and Perceptions of Autonomy: Examples from Molyko Neighbourhood, South West Region, Cameroon", in M. Ntarangwi and G. Massart (eds.), Engaging Children and Youth in Africa: Methodological and Phenomenological (Bameda: Langaa Research \& Publishing, 2015), 169-85.

Mourtada, R., Schlecht, J. and Dejong, J., “A Qualitative Study Exploring Child Marriage Practices among Syrian Conflict-Affected Populations in Lebanon", Conflict and Health 2017 (11), 53-65. 
Murphy-Graham, E. and Leal, G., "Child Marriage, Agency, and Schooling in Rural Honduras", Comparative Education Review 2015 (59(1)), 24-49.

Nasrullah, M., Zakar, R. and Krämer, A., "Effect of Child Marriage on Use of Maternal Health Care Services in Pakistan", Obstetrics \& Gynecology 2013 (122(3)), 517-24.

Noggle, R., "Special Agents: Children's Autonomy and Parental Authority”, in D. Archard and C. Macleod (eds.), The Moral and Political Status of Children (Oxford: Oxford University Press, 2002), 97-116.

Notermans, C., "Sharing Home, Food and Bed: Paths of Grand Motherhood in East Cameroon", Africa:Journal of the International African Institute 2004 (74(1)), 6-27. oECD Development Centre, Social Institutions and Gender Index: Somalia (2019).

Paul, P., "Effects of Education and Poverty on the Prevalence of Girl Child Marriage in India: A District-Level Analysis", Children and Youth Services Review 2019 (100), $16-21$.

Plan International (2011), Breaking vows: early and forced marriage and girls' education.

Plan International Australia (2018), Half a billion reasons: how investing in adolescent girls can change the world.

Plan UK (2013), Before their time: Challenges to Implementing the Prohibition Against Child Marriage in Sierra Leone.

Raj, A. et al., "The Effect of Maternal Child Marriage on Morbidity and Mortality of Children under 5 in India: Cross Sectional Study of a Nationally Representative Sample", $B M J(340)$, 1-9.

Save the Children (2019), "No I don't". Abolishing child marriage in Lebanon. Policy Note. Sekine, K. and D.J. Carter, D.J., "The Effect of Child Marriage on the Utilization of Maternal Health Care in Nepal: A Cross-Sectional Analysis of Demographic and Health Survey", PLoS ONE 2019 (14(9)), 1-13.

Shahnaz, R. and R. Karim, R., Providing Microfinance and Social Space to Empower Adolescent Girls: An Evaluation of BRAC'S ELA Centres (No. 3) (2008).

Shepler, S., Childhood Deployed: Remaking Child Soldiers in Sierra Leone (New York: New York University Press. 2014).

Sinha, N. and Yoong, J., Long-Term Financial Incentives and Investment in Daughters: Evidence from Conditional Cash Transfers in North India (No. 486o), Policy Research Working Paper (2009).

Spivak, G.C., "Can the Subaltern Speak?”, in P. Williams and L. Chrisman (eds.), Colonial Discourse and Post-Colonial Theory: A Reader (Hertfordshire: Harvester Wheatsheaf, 1994).

Taylor, A.Y. et al., "Child Marriages and Unions in Latin America: Understanding the Roles of Agency and Social Norms", Journal of Adolescent Health 2019 (64(4)), S45-51. Thomson, S., "Agency as Silence and Muted Voice: The Problem-Solving Networks of Unaccompanied Young Somali Refugee Women in Eastleigh, Nairobi", Conflict, Security and Development 2013 (13(5)), 589-6o9. 
UN Committee on the Rights of the Child (2003), CRC General Comment No. 4: Adolescent Health and Development in the Context of the Convention on the Rights of the Child.

UNFPA (2011a), Girls power and potential: a joint programming framework for fulfilling the rights of marginalized adolescent girls.

UNFPA (2011b), "Unleashing the Power and Potential of Adolescent Girls".

UNFPA (2015), Girlhood, Not Motherhood: Preventing Adolescent Pregnancy.

UNFPA and UNICE F (2019), 2018 Annual Report. Turning Commitments into Solid Actions. UNFPA-UNICEF Global Programme to Accelerate Action to End Child Marriage.

UNICEF (2005), Early marriage: a harmful tradition practice. A statistical exploration.

UNICEF (2018), Child marriage: latest trends and future prospects.

UNICEF and International Center for Research on Women (2017), Child Marriage in the Middle East and North Africa.

UniCEF Somalia and Somaliland Ministry of Planning and National Development (2014), Somaliland Multiple Indicator Cluster Survey 2011, Final Report.

United Nations General Assembly (1989), Convention on the Rights of the Child.

United Nations Population Fund (UNFPA) (2020), Technical Note on Scaling Up Efforts to End Child Marriage: The Global Programme Approach.

Vaha, M.E. and L. Vastapuu, L., "'My Heart Was Already Cooked': Girl Soldiers and Situated Moral Agencies", Cambridge Review of International Affairs 2018 (31(2)), 223-38.

Van der Sijpt, E. and Notermans, C., "Perils to Pregnancies: On Social Sorrows and Strategies Surrounding Pregnancy Loss in Cameroon", Medical Anthropology Quarterly 2010 (24(3)), 381-98.

Warner, A., Stoebenau, K. and A.M. Glinski, A.M., More power to her: how empowering girls can help end child marriage (2016).

Watson, C., Understanding changing social norms and practices around girls'education and marriage (2014).

World Bank (2014), "Adolescent Girls Initiative".

World Vision (2008), Before She's Ready. ${ }_{5}$ Places Girls Marry by 15.

World Vision (2019), New Vows: Empowering Communities to End Child Marriage.

World Vision UK (2013), Untying the Knot: Exploring Early Marriage in Fragile States. 